\title{
"Plug: Secrets of the Museum": A Pervasive Game Taking Place in a Museum
}

\author{
Michel Simatic ${ }^{1}$, Isabelle Astic ${ }^{2}$, Coline Aunis ${ }^{2}$, Annie Gentes ${ }^{1}$, \\ Aude Guyot-Mbodji ${ }^{1}$, Camille Jutant ${ }^{1}$, and Emmanuel Zaza ${ }^{3}$ \\ 1 Institut TELECOM, 46 rue Barrault, 75634 Paris Cedex 13, France \\ gentes@telecom-paristech.fr, audeguyot@gmail.com, \\ camillemontreal@gmail.com, michel.simatic@it-sudparis.eu \\ 2 Musée des arts et métiers, 292 rue Saint-Martin, 75141 Paris Cedex 03, France \\ \{isabelle.astic, coline.aunis\}@cnam.fr \\ 3 TETRAEDGE Games, 54 rue Marceau, 93100 Montreuil, France \\ ezaza@tetraedge.com
}

\begin{abstract}
Plug: Secrets of the Museum" (PSM) is a game played with NFC-enabled mobile phones inside a museum containing dedicated passive RFID tags. During a PSM session, 8 teams exchange virtual cards representing objects located in the museum. These exchanges are done either with RFID tags or with other teams. PSM game design results in an educational and entertaining game which is much more attractive than the plain old treasure hunt proposed by several museums. Thus PSM is a good companion to discover and even take up a museum.
\end{abstract}

\section{Introduction}

Museums intend to arouse visitors' interest in their pieces. Computer games can contribute to this mission [1].

23 present examples of such games. None of them meet simultaneously all of the following requirements: 1) the game is educational but also entertaining; 2) installation and operating costs are limited; 3) it can be played by anyone (whatever their age and their social category); 4) it is a family game; 5) the same player can play several times without getting bored.

This is why we have developed "Plug1: Secrets of the Museum" (PSM). Section 2 presents its game design and how it matches all of the requirements. Section 3 concludes.

\section{Game Description}

In PSM, 8 teams play with NFC-enabled handsets. They manipulate virtual playing cards, which represent specific objects of the museum. These cards are stored either on handsets, or on RFID tags located besides these objects.

\footnotetext{
${ }^{1}$ PLUG is a research project funded by $A N R$ and labelled by Cap Digital. Its contributors are academics (CNAM, Institut TELECOM, Université de La Rochelle), companies (Net Innovations, Orange, TETRAEDGE Games), a museum (Musée des arts et métiers) and an association (Dune-Aventure).
} 
The goal is to get the best score throughout the game session. To gain points, the teams may prove: their collector's ability, by gathering on their handset 4 cards of the same family (through exchanges "card stored in their handset $\Leftrightarrow$ card stored in a RFID tag" or "card stored in their handset $\Leftrightarrow$ card stored in another teams handset"); their public-spiritedness, by storing a card to its reference RFID tag (thanks to an exchange "card stored in their handset $\Leftrightarrow$ card stored in a RFID tag"); their generosity, by exchanging one of their cards with another team; their curiosity, by answering quiz related to the objects of the Museum.

PSM is educational as, in particular, players discover parts of the museum they would not have paid attention to, if they had not played PSM. Nevertheless players considered it as very entertaining.

Installation of PSM consists in the deployment of tags throughout the museum. Moreover no network is needed at game time. This results in limited installation and operating costs.

Because there are several ways of gaining points, PSM reaches a broad audience (e.g. young children like its collector aspect whereas seniors enjoy quiz).

PSM suits a family visit. Family members can choose to play either together (in the same team), or against each other (in different teams).

A player can play several sessions of PSM without getting bored: each time, they can decide to choose a different strategy (focus on generosity points, focus on curiosity points...). Moreover their competitors will always be different and this will give a different thrill to each session.

\section{Conclusion}

12 public game sessions (with 150 players) showed that PSM makes players take up the whole museum. PSM gives them the desire to stay after their session, in order to focus on some parts of the museum discovered during the game.

During ICEC 2009, we intend to demonstrate PSM by making participants play PSM sessions in the Musée des arts et métiers museum.

PSM key concept is to collect cards through exchanges with RFID tags or other teams. This concept can be generalized easily to any kind of museums, with limited installation and operating costs. Thanks to PSM's educational but also entertaining features, one of the main missions of museums (arouse visitors' interest in their contents) is fulfilled.

\section{References}

1. Gupta, A.: The End of the Game, a Mystery in Four Parts. Smithsonian.com (December 2008),

http://www . smithsonianmag. com/arts-culture/The-End-Of-The-Game-AMystery-In-Four-Parts.html

2. Heumer, G., Gommlich, F., Jung, B., Müller, A.: Via Mineralia - a pervasive museum exploration game. In: Proc. of Pergames 2007, Salzburg, AT (2007)

3. Laurillau, Y., Paternó, F.: Supporting museum co-visits using mobile devices. In: Brewster, S., Dunlop, M.D. (eds.) Mobile HCI 2004. LNCS, vol. 3160, pp. 451-455. Springer, Heidelberg (2004) 